Revista Brasileira de Agricultura Irrigada v.11, nº.5, p. 1707 - 1713, 2017

ISSN 1982-7679 (On-line)

Fortaleza, CE, INOVAGRI - http://www.inovagri.org.br

DOI: $10.7127 /$ rbai.v11n500761

Protocolo 761.17 - 23/05/2017 Aprovado em 31/08/2017

\title{
ANÁLISE DAS CARACTERÍSTICAS AGRONÔMICAS E MICROBIOLÓGICAS DO FEIJÃO-CAUPI ( Vigna ungiculada (L.) Walp. ) BRS NOVAERA E BRS GUARIBA COM APLICAÇÃO DE ÁGUA RESIDUÁRIA TRATADA.
}

\author{
Gregorio Guirado Faccioli ${ }^{1}$, Francyelle Souza de Menezes Ramos ${ }^{2}$, Fabiano Santos Santana ${ }^{3}$, \\ Camila Kaliane dos Santos Dantas ${ }^{4}$
}

\begin{abstract}
RESUMO
Com o objetivo de economizar água de primeira qualidade no mundo o reuso de águas residuárias vem sendo praticado; a reutilização do recurso natural torna-se cada vez mais necessário. Assim, este trabalho tem como objetivo avaliar a viabilidade do reuso de efluentes provenientes de um sistema de tratamento de esgotos por lagoas de estabilização na irrigação do Feijão-Caupi (Vigna ungiculata (L.) Walp.), por meio de características agronômicas e microbiológicas da cultura. A pesquisa foi desenvolvida em casa de vegetação, localizada na Universidade Federal de Sergipe. O delineamento experimental foi em Blocos Casualizados (DBC) composto por três tratamentos (100\% água potável; 100\% efluente; e 50\% água da potável $+50 \%$ efluente), com duas variedades de feijão, Caupi Brs Novaera e Caupi Brs Guariba, quatro repetições, totalizando 24 vasos. O uso de água residuária tratada na irrigação da cultura do feijão caupi não influenciou nas características agronômicas avaliadas ao nível de significância de $5 \%$. Verificando os resultados das análises de coliformes a $45^{\circ} \mathrm{C}$, Salmonellas e Staphylococus Aureus realizadas em laboratório e comparando com os níveis máximos admitidos pela Resolução 12/2001 da Anvisa para a cultura do feijão Caupi Brs Novaera conclui-se que os valores determinados em laboratório são inferiores aos parâmetros estabelecidos pela ANVISA, portanto é viável a utilização da água residuária para a irrigação da cultura do feijão.
\end{abstract}

Palavras-chave: reuso de água, otimização de recursos naturais, estação de tratamento de esgoto.

\footnotetext{
${ }^{1}$ Prof. Dr. Departamento de Engenharia Agrícola, UFS, São Cristovão - SE, Brasil, Avenida Marechal Rondon sn, CEP 49100-000, e-mail: gregorioufs@gmail.com

${ }^{2}$ Graduanda em Engenharia Agrícola, UFS, São Cristovão - SE, Brasil, Avenida Marechal Rondon sn, CEP 49100000, e-mail: francyelle_ramos10@hotmail.com

${ }^{3}$ Graduando em Engenharia Agrícola, UFS, São Cristovão - SE, Brasil, Avenida Marechal Rondon sn, CEP 49100000, e-mail: engagrifabiano-ufs@hotmail.com

${ }^{4}$ Graduanda em Engenharia Agrícola, UFS, São Cristovão - SE, Brasil, Avenida Marechal Rondon sn, CEP 49100000, e-mail: camilakaliane@hotmail.com.br
} 


\title{
ANALYSIS OF AGRONOMIC AND MICROBIOLOGICAL CHARACTERISTICS OF CAUPI BEAN (Vigna ungiculada (L.) Walp.) BRS NOVAERA AND BRS GUARIBA WITH APPLICATION OF WASTEWATER TREATED.
}

\begin{abstract}
In order to save water of the first quality in the world, wastewater reuse has been practiced; The re-use of the natural resource becomes more and more necessary. This work aims to evaluate the wastewater reuse feasibility from a sewage treatment system stabilization ponds for irrigation Caupi bean (Vigna ungiculata (L.) Walp.), Through agronomic and microbiological characteristics culture. The research was conducted in a greenhouse in the Federal University of Sergipe. The experimental design was randomized blocks (DBC) consists of three treatments (100\% drinking water, $100 \%$ effluent, and 50\% drinking water $+50 \%$ effluent) with two varieties of Caupi bean, Brs Novaera and Brs Guariba four repetitions, totaling 24 vessels. The use of treated wastewater for irrigation of Caupi bean did not influence the agronomic traits with $5 \%$ significance level. Checking the results of the analysis of coliforms at $45^{\circ} \mathrm{C}$, Salmonella and Staphylococcus Aureus held at laboratory and compared to the maximum levels allowed by Anvisa Resolution 12/2001 for the Caupi Bean Brs Novaera it is concluded that the values determined in laboratory They are lower than the standards established by ANVISA, so it is feasible to use wastewater for irrigation of bean crop.
\end{abstract}

Keywords: water reuse, natural resource optimization, sewage treatment plant.

\section{INTRODUÇÃO}

Com o aumento da população mundial faz-se necessário uma maior produção de alimentos, crescendo o desenvolvimento agrícola e exigindo novas estratégias para que haja potencialização e menores riscos na produção. Sendo assim a produção de alimentos com base apenas na estação chuvosa não é suficiente. Um dos importantes desafios da agricultura atual é o aumento da competitividade e qualidade dos produtos, associado à preservação dos recursos hídricos e do meio ambiente, permitindo benefícios sustentáveis nas explorações agrícolas. Avaliar e adequar cada um dos fatores que compõem o sistema de produção, incluindo a eficiência e o manejo da água de irrigação é um fator importante visto que atualmente, a agricultura tem sido responsável por grande parcela da água utilizada, tornando necessária a implantação de sistemas de irrigação eficientes, além da utilização de métodos que quantifiquem as necessidades hídricas das culturas, para que não haja desperdício de água e de energia. (FACCIOLI, 1998).
A agricultura irrigada vem se tornando, nos últimos anos, uma das atividades econômicas mais importantes no Brasil. A grande quantidade de água requerida pela irrigação e o decréscimo da disponibilidade tem aumentado o interesse pela racionalização desse recurso, a falta de recursos hídricos e o aumento dos conflitos pelo uso da água gera a preocupação em conservar a água doce e intensificar o tratamento da água já usada para ser reutilizada.

São inúmeros os benefícios da água de reuso proveniente de tratamento de esgotos na agricultura, o reuso oferece muitas vantagens para o setor agrícola, apesar da possibilidade de risco de contaminação deve-se ter cuidado aos riscos à saúde pública, que se associa aos agentes patogênicos que podem estar presentes nas águas de esgoto para reuso.

Segundo Hespanhol (2003), o reuso planejado de águas é uma alternativa potencial de racionalização desse bem natural. $\mathrm{O}$ autor destaca a importância de institucionalizar, regulamentar e promover o reuso de água no Brasil, fazendo com que a prática seja desenvolvida de acordo com princípios técnicos adequados, que seja economicamente 
viável, ambientalmente sustentável e socialmente aceita e segura, em termos de preservação ambiental e de proteção dos grupos de riscos envolvidos.

O feijão-caupi (Vigna unguiculata), também conhecido como feijão de praia, feijão- de-corda ou feijão-macassar, é um alimento rico em proteínas, vitaminas, minerais e representa uma importante fonte nutricional na alimentação dos brasileiros, agregando importância econômica e social na sua cadeia produtiva e comercial. Pertencente à família botânica das leguminosas, o feijão-caupi representa excelente alternativa para o cultivo, em rotação ou em consórcio com outras culturas. A cultivar BRS Novaera tem grãos brancos, graúdos e bem formados, no padrão de preferência de uma grande faixa de consumidores, tanto no mercado nacional quanto no mercado internacional. $\mathrm{O}$ tegumento rugoso é o que o diferencia visualmente da cultivar Guariba. O feijão-caupi BRS Guariba possui tegumento branco, é resistente a diversas doenças e tem boa adaptabilidade em diferentes ecossistemas do país, sobretudo nas regiões Nordeste, Norte e Centro- Oeste, onde vem aumentando sua área de produção principalmente como opção para cultivo em safrinha. O mercado de feijão- caupi cresce ano a ano, e recentemente a cultivar BRS Guariba foi exportada para países como Índia, Turquia, Canadá, Portugal, Israel e Egito, onde teve grande aceitação.

Neste contexto, o trabalho teve como objetivo geral analisar as características agronômicas e microbiológicas do Feijão Caupi (Vigna ungiculata L. Walp.), Brs Novaera e Brs Guariba irrigado com água residuária tratada.

\section{MATERIAL E MÉTODOS}

O experimento foi conduzido em casa de vegetação, no período de janeiro a julho de 2015, localizada no Departamento de Engenharia Agronômica da Universidade Federal de Sergipe, no município de São Cristóvão, Sergipe sob as coordenadas geográficas de $10^{\circ} 55^{\prime} 46^{\prime} \mathrm{S}$ latitude e $37^{\circ} 06^{\prime} 13^{\prime}$ OO longitude (Figura 1).

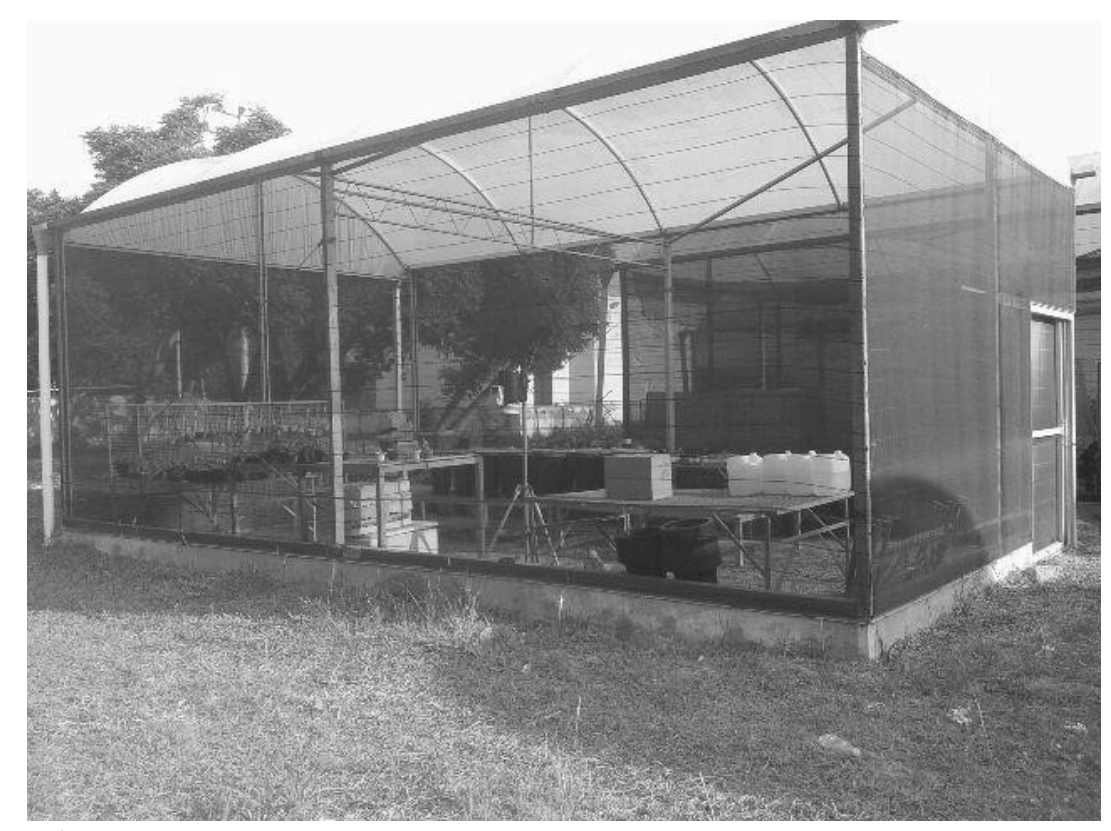

Figura 1. Vista lateral da casa de vegetação utilizada no experimento (DEA/UFS).

Fonte: Registro fotográfico obtido durante o experimento, 2015.

Dentro da casa de vegetação foi instalada uma estação meteorológica automática para coleta de dados climáticos (temperaturas, umidade relativa, radiação solar e velocidade do 
vento) que foram utilizados diariamente para a estimativa da demanda hídrica da cultura.

O delineamento experimental utilizado foi em Blocos Casualizados (DBC) composto por três tratamentos, com duas variedades de feijão, Caupi Brs Novaera e Caupi Brs Guariba, quatro repetições, totalizando 24 vasos. Os tratamentos seguiram dessa forma T1 (100\% água potável); T2 (50\% água potável + 50\% efluente); e T3 (100\% efluente).

No dia 09 de fevereiro de 2015 foram realizados, simultaneamente, o plantio e a adubação. As sementes utilizadas foram sementes certificadas. Como procedimento foram plantadas 3 sementes.vaso $^{-1}$ em fileira no meio do vaso. Após a semeadura, foi realizada a irrigação de saturação, até a germinação de todas as sementes, composta por $400 \mathrm{~mL}$ de água potável duas vezes por dia, buscando a possibilidade de germinações uniformes e um bom desenvolvimento. $\mathrm{Na}$ adubação de plantio todos os tratamentos receberam Cloreto de potássio nos valores de 0,48 g.vaso $^{-1}$ e de MAP 1,1 g.vaso $^{-1}$.

O efluente utilizado neste trabalho é proveniente de uma Estação de Tratamento de Esgoto (ETE) que é alimentada pelo esgoto sanitário em dois pontos: um na lagoa facultativa primária, que representa a maior contribuição do sistema, recebendo o esgoto proveniente da estação elevatória; outro na lagoa facultativa secundária, que recebe o esgoto por gravidade. Em ambos pontos, o esgoto chega na unidade de pré-tratamento, composto por grade e caixa de areia, sendo então encaminhado às lagoas.

A irrigação foi realizada diariamente com auxílio de uma proveta de $100 \mathrm{~mL}$ diretamente no vaso. O volume a ser irrigado foi definido diariamente pelo método padrão FAO 56 (ALLEN, 1998).

A colheita foi realizada no dia 09 de abril com 60 dias após a semeadura quando as vagens já estavam totalmente secas. Foram retiradas manualmente e guardadas em sacos plásticos.
As características agronômicas analisadas foram altura, massa seca da parte aérea, número de vagens e peso de 100 grãos por tratamento. Durante a colheita a altura da planta foi medida com trena, e foi realizada a partir de sua base até seu ápice. Depois da colheita foi feito o corte da cultura para separar a parte aérea da raiz. Posteriormente a parte aérea foi acondicionadas em sacos de papel e encaminhadas para o laboratório de Remediação do Departamento de Engenharia Agronômica para secagem em estufa ventilada a $65^{\circ} \mathrm{C}$. Também foi contado o número de vagens por planta, e medido o peso do total de grãos de cada planta e o peso de 100 grãos por tratamento.

Depois das pesagens foram calculadas as médias de cada tratamento, para a análise de variância (ANOVA). A ANOVA foi realizada utilizando o software estatístico SISVAR, com teste de média Tukey a 5\% de probabilidade.

As analises microbiológicas analisadas foram Coliformes, Salmonella e Staphilococus Aureus. Depois das pesagens os grãos foram encaminhados para o ITPS (Instituto Tecnológico e de Pesquisas do Estado de Sergipe) para serem feitas as análises microbiológicas. Segundo a legislação 12/01 da ANVISA não se faz analises microbiológicas em grãos inteiros. As amostras foram encaminhadas para o laboratório de remediação no Departamento de Agronomia e moídas por um moedor devidamente higienizado.

\section{RESULTADOS E DISCUSSÕES}

Pela análise de variância e teste de média realizada pelo software SISVAR observou- se que na massa seca da parte aérea do feijão os tratamentos T1, T2 e T3 não apresentaram diferenças significativas a $5 \%$ de probabilidade. Portanto o uso do efluente não influenciou no desenvolvimento da parte aérea da cultura do feijão Caupi Brs Novaera e Brs Guariba. (Tabela 01).

Tabela 01 - Valores obtidos pelo teste de média da massa seca parte aérea.

\begin{tabular}{cccc}
\hline & NOVAERA & \multicolumn{2}{c}{ GUARIBA } \\
\hline T1 & $14.847500 \mathrm{a} 1$ & T3 & $17.010000 \mathrm{a} 1$
\end{tabular}




\begin{tabular}{cccc} 
T3 & $14.870000 \mathrm{a} 1$ & T2 & $17.100000 \mathrm{a} 1$ \\
T2 & $15.317500 \mathrm{a} 1$ & T1 & $20.295000 \mathrm{a} 1$ \\
\hline
\end{tabular}

Segundo Dantas (2014), também trabalhando com água residuária da mesma fonte do ETE do Rosa Elze não encontrou diferenças significativas a $5 \%$ de probabilidade pelo teste de Tukey na massa seca da parte aérea e na altura da planta.

Pela análise de variância e teste de média realizada pelo software SISVAR observou-se que na altura do feijão os tratamentos T1, T2 e T3 não apresentaram diferenças significativas a $5 \%$ de probabilidade. Portanto o uso do efluente não influenciou no desenvolvimento da altura da cultura do feijão Caupi Brs Novaera e Brs Guariba. (Tabela 02).

Tabela 02 - Valores obtidos pelo teste de média da altura do feijão.

\begin{tabular}{cccc}
\hline \multicolumn{2}{c}{ NOVAERA } & \multicolumn{2}{c}{ GUARIBA } \\
\hline T1 & $53.750000 \mathrm{a} 1$ & T2 & $63.750000 \mathrm{a} 1$ \\
T3 & $55.000000 \mathrm{a} 1$ & T1 & $65.750000 \mathrm{a} 1$ \\
T2 & $55.000000 \mathrm{a} 1$ & T3 & $77.500000 \mathrm{a} 1$ \\
\hline
\end{tabular}

Esse resultado difere do trabalho de Alves et al. (2012), que ao avaliar a possibilidade do uso de água residuária do esgoto doméstico na produção de mudas de tomate por meio das variáveis, número de folhas, área foliar, diâmetro do coleto, altura da parte aérea e massa seca total, todas as variáveis analisadas apresentaram diferenças significativa, e as mudas mais vigorosas foram obtidas na maior concentração de água residuária na irrigação.
Pela análise de variância e teste de média realizada pelo software SISVAR observou-se que no número de vagens do feijão os tratamentos $\mathrm{T} 1$, T2 e T3 não apresentaram diferenças significativas a $5 \%$ de probabilidade. Portanto o uso do efluente não influenciou no desenvolvimento do número de vargens da cultura do feijão Caupi Brs Novaera e Brs Guariba. (Tabela 03).

Tabela 03 - Valores obtidos pelo teste verificando o número de vagens.

\begin{tabular}{cccc}
\hline & NOVAERA & & GUARIBA \\
\hline T1 & $10.750000 \mathrm{a} 1$ & T3 & $6.000000 \mathrm{a} 1$ \\
T3 & $11.000000 \mathrm{a} 1$ & T2 & $6.000000 \mathrm{a} 1$ \\
T2 & $12.500000 \mathrm{a} 1$ & T1 & $7.250000 \mathrm{a} 1$ \\
\hline
\end{tabular}

Segundo Cunha et al. (2015), trabalhando com o cultivo do feijão irrigado com água residuária não houve diferença significativa ao nível de $5 \%$ de probabilidade pelo teste de Tukey entre os tratamentos com diferentes doses de boro o número de vagens foram estatisticamente iguais.
Pela análise de variância e teste de média realizada pelo software SISVAR observou-se que no peso dos grãos do feijão não apresentaram diferenças significativas a $5 \%$ de probabilidade. Portanto, o uso do efluente não influenciou no peso dos grãos da cultura do feijão Caupi Brs Novaera e Brs Guariba. (Tabela 04).

Tabela 04 - Valores obtidos pelo teste de média no peso dos grãos.

\begin{tabular}{cccc}
\hline & NOVAERA & \multicolumn{2}{c}{ GUARIBA } \\
\hline T1 & $16.165000 \mathrm{a} 1$ & T3 & $15.070000 \mathrm{a} 1$
\end{tabular}




$\begin{array}{llll}\text { T2 } & 16.935000 \mathrm{a} 1 & \text { T1 } & 15.895000 \mathrm{a} 1 \\ \text { T3 } & 17.072500 \mathrm{a} 1 & \text { T2 } & 16.275000 \mathrm{a} 1\end{array}$

Segundo Cunha et al. (2015), trabalhando com o cultivo do feijão irrigado com água residuária não houve diferença significativa ao nível de $5 \%$ de probabilidade pelo teste de Tukey entre os tratamentos com diferentes doses de boros portanto não influenciou na produtividade do feijão. A Tabela 05 podem ser observados os valores obtidos pela análise das variáveis microbiológicas da cultura do feijão caupi Brs Novaera realizada pelo ITPS.

Tabela 05 - Resultados obtidos NMP/g de coliformes totais, ausência em 25g de Salmonella e UFC/g Staphylococus Aureus para. Tratamentos: 1(100\% água DESO), 2 (50\% água DESO + 50\% efluente), 3(100\%efluente).

\begin{tabular}{cccc}
\hline Tratamentos & T1 & T2 & T3 \\
\hline Coliformes (NMP/g) & $\leq 3$ & $\leq 3$ & $\leq 3$ \\
Salmonella (ausência em 25g) & Ausente & Ausente & Ausente \\
Staphylococus Aureus (UFC/g) & $<10$ & $<10$ & $<10$ \\
\hline
\end{tabular}

Observa-se pela Tabela 05 que os valores obtidos apresentam-se inferiores estabelecidos pela normativa 12 de 2001 da ANVISA. Os limites aceitáveis para a cultura do feijão são: para coliformes $10 \mathrm{NMP} / \mathrm{g}$, para salmonela ausência em 25g e para Staphylococus Aureus $100 \mathrm{UFC} / \mathrm{g}$. Sendo assim, é possível constatar que o uso de água de reuso de origem urbana, não apresentou interferências sobre as características microbiológicas para o feijão Caupi Brs Novaera.

Porém, pesquisas desenvolvidas por Rego et al. (2005), com a irrigação da melancia com efluente tratado, mostraram, em todos os frutos testados, a ausência de salmonelas e baixos valores de coliformes fecais, independente dos sistemas de irrigação utilizado, atendendo, assim, os limites fixados pela Agência Nacional de Vigilância Sanitária (ANVISA, 2001). Logo, não foi verificado comprometimento da qualidade microbiológica dos produtos analisados, classificando-os aptos ao consumo humano.

A Tabela 06 podem ser observados os valores obtidos pela análise das variáveis microbiológicas da cultura do feijão caupi Brs Guariba realizada pelo ITPS, sendo elas Coliformes, Salmonella e Staphilococus Aureus.

Tabela 06 - Resultados obtidos NMP/g de coliformes totais, ausência em $25 \mathrm{~g}$ de Salmonella e UFC/g Staphylococus Aureus para. Tratamentos: 1(100\% água DESO), 2 (50\% água DESO + 50\% efluente), 3(100\%efluente).

\begin{tabular}{cccc}
\hline Tratamentos & T1 & T2 & T3 \\
\hline Coliformes (NMP/g) & $\leq 3$ & $\leq 3$ & $>1,1 \times 10^{3}$ \\
Salmonella (ausência em 25g) & Ausente & Ausente & Ausente \\
Staphylococus Aureus (UFC/g) & $<10$ & $<10$ & $<10$ \\
\hline
\end{tabular}

Observa-se pela Tabela 06 que os valores obtidos apresentam-se inferiores estabelecidos pela normativa 12 de 2001 da ANVISA com exceção de coliformes para o tratamento T3 (100\% efluente), o porquê do não atendimento deste parâmetro pode ter acontecido por fatores desconhecidos entre eles, pela contaminação da amostra no 
processo de moagem ou em outra etapa de preparação. Os limites aceitáveis para a cultura do feijão são: para coliformes $10 \mathrm{NMP/g}$, para salmonela ausência em $25 \mathrm{~g}$ e para Staphylococus Aureus $100 \mathrm{UFC} / \mathrm{g}$. Sendo assim, é possível constatar que o uso de água de reuso de origem urbana, não apresentou interferências sobre as características microbiológicas para o feijão Caupi- Brs Guariba. Observa-se que o efluente não alterou os padrões microbiológicos para o consumo do feijão.

Os resultados obtidos no presente estudo relacionados ao acima abordado, corroboram com as observações realizadas por $\mathrm{Al}$ nakshabandI et al. (1997) e Emongor (2004), quando esses autores constataram a ausência de Coliformes fecais, Salmonela sp., Shigela sp. e E. coli em todas as amostras analisadas de berinjela e tomate irrigado com águas residuárias tratadas.

\section{CONCLUSÕES}

O uso de água residuária tratada na irrigação da cultura do feijão Caupi Brs Novaera e Brs Guariba não influenciou nas características agronômicas avaliadas com nível de significância de 5\%.

Os valores determinados em laboratório são inferiores aos parâmetros estabelecidos pela ANVISA, portanto é viável a utilização da água residuária para a irrigação da cultura do Feijão.

\section{REFERÊNCIAS}

ALLEN, R. G.; PEREIRA, L. S.; RAES, D.; SMITH. M. Crop evapotranspiration Guidelines for computing crop water requirements. In: FAO Irrigation and DrainagePaper 56. Rome: FAO, 1998.

ALVES, R. C.; NETO, M. F.; NASCIMENTO, M. L.; OLIVEIRA, M. K. T.; LINHARES, P. S. F.; CAVALCANTE, J. S. J.; OLIVEIRA, F. A. Reutilização de água residuária na produção de mudas de tomate. Agropecuária Científica no Semi-Árido, v.8, n.4, p 77-81, 2012.

AL-NAKSHABANDI, G. A.; SAQQAR, M. M.; SHATANAWI. M. R.; FAYYAD, M.; ALHORANI, H. Some envirommental problems associated with the use treated wastewater for irrigation in Jordan. Agricultural Water Management, v. 34, p.81-94, 1997.

CUNHA, A. H. N.; GOMES, F. P.; ARAÚJO, C. S. T.; CARDOSO, A. O.; VALENTE, M. S. Cultivo de feijão irrigado com água residuária e adubado com micronutrientes. Revista

Mirante, v. 8, n. 1, p.48-59, 2015.

DANTAS, I. L. A.; FACCIOLI, G. G.; MENDONÇA, L. C.; NUNES, T. P.; VIEGAS, P. R. A.; SANTANA, L. O. G. Viabilidade do uso de água residuária tratada na irrigação da cultura do rabanete (Raphanus sativus L.). Revista Ambiente e Água, v. 9 n.1, P.109-117, 2014.

EMONGOR, V. E.; RAMOLEMANA, G. M. Treated sewage effluent (water) potential to be used for horticultural production in Botswana. Physics and chemistry of the earth, Oxford, v.29, p.1101-1108, 2004.

FACCIOLI, G. G. Determinação da evapotranspiração de referência e da cultura da alface em condições de casa de vegetação, em Viçosa, MG. Universidade Federal de Viçosa, 1998.

HESPANHOL, I. Potencial de reuso de água no Brasil: agricultura, indústria, município e recarga de aquíferos. In: MANCUSO, P. C. S. \& SANTOS, H. F. (editores). Reuso de água. Barueri-SP: Manole, p.37-95, 2003.

REGO, J. L.; OLIVEIRA, E. L. L.; CHAVES, A, F.; ARAÚJO, A. P. B.; BEZERRA, F. M. L.; SANTOS, A. B.; MOTA, S. Uso de esgoto doméstico tratado na irrigação da cultura da melancia. Revista Brasileira de Engenharia grícola e Ambiental, Campina Grande, v.9, (Suplemento), p.155-159, 2005. 